\title{
The Trypanosomatid Evolution Workshop London School of Hygiene and Tropical Medicine 17-18 February 2000
}

\author{
Jamie Stevens \\ Hatherly Laboratories, School of Biological Sciences, University of Exeter Prince of Wales Road, \\ Exeter EX4 4PS, UK
}

The trypanosome evolution workshop, a joint meeting of the University of Exeter and the London School of Hygiene and Tropical Medicine, focused on topics relating to trypanosomatid and vector evolution. The meeting, sponsored by The Wellcome Trust, The Special Programme for Research and Training in Tropical Disease of World Health Organization and the British Section of the Society of Protozoologists, brought together an international group of experts who presented papers on a wide range of topics including parasite and vector phylogenies, molecular methodology and relevant biogeographical data.

Key words: trypanosomatid - vector - evolution

\section{BACKGROUND}

Since the beginning of the 20th century, when the phylogenetic relationships of trypanosomes were first considered, debate concerning the evolution of pathogenic trypanosomes has centred around two opposing hypotheses: 'invertebrate first' (Léger 1904) or 'vertebrate first' (Minchin 1908), depending on which was the original host of the monogenetic parasite. Early research was based largely on parasite morphology and biological criteria (e.g. pathogenicity and host range), and most parasitologists tended to favour the former hypothesis (Baker 1963, Hoare 1972). The application of biochemical characterization techniques in the early 1970s, set the scene for the use of more powerful molecular techniques, and sequence-based evolutionary studies have now been undertaken for nearly all major groups of trypanosomatids. However, the resulting molecular phylogenies are consistent with both the vertebrate or invertebrate first hypotheses, since both genus Trypanosoma and the branch leading to the monogenetic parasites arise from the root of the

This meeting was made possible by financial support from the Wellcome Trust and the Special Programme for Research and Training in Tropical Disease programme of the World Health Organization, with additional support from the British Section of the Society of Protozoologists.

Fax: +44 1392 263700. E-mail: j.r.stevens@ex.ac.uk.

Received 13 April 2000

Accepted 15 May 2000 trypanosomatid tree, and such results have effectively turned the original debate on its head (Stevens et al. 2000).

More recently, it has become apparent that it is impossible to accurately date the timing of certain key divergence events using only trees because of the unreliability of the molecular clocks used to calibrate such trees over large periods of geological time. Consequently, many researchers are now turning to other, independent methods for calibrating molecular trees and dating key branching events. Included in these are the integrated study of host-parasite phylogenies and vicariance biogeography (Stevens et al. 1999).

\section{THE MEETING}

The workshop provided a forum for workers in the field of trypanosomatid and vector evolution to meet and to discuss their many varied approaches to evolutionary research, with the aim of breaking down the compartmentalisation which is all too often apparent in this field.

Some of the fundamental questions to be addressed were: (1) What are the ancient origins of trypanosomatids and when did they emerge? (2) What are the relationships between the major groups such as the trypanosomes and the leishmanias or between the subgenera Trypanozoon and Schizotrypanum, or within the possibly polyphyletic subgenus Megatrypanum? (3) Is trypanosomatid evolution primarily associated with the evolution of the arthropod vector, or of the vertebrate host, or of both? (4) How can events in trypanosomatid evolution be dated reliably, for example the age of $T$. rangeli compared to that of $T$. 
cruzi, or the age of haematophagous triatomine bugs in the Americas? (5) Can major divergence events between parasite groups be associated and/or explained by reference to known bio/palaeogeographical events? (6) Are the molecular markers commonly employed (e.g. 18S rRNA) suitable for the job? (7) Are the trees informative - have appropriate outgroups been identified to allow the construction of robust phylogenies?

Based on these questions, the key aims of the meeting were to identify common approaches for studying trypanosomatid and vector evolution, and to attempt to formulate an agreed chronological framework within which major evolutionary events in the history of both parasites and vectors can be assumed to have occurred. It was to be hoped that such a framework would provide a basis for future research. With this aim, the meeting was loosely organised into three sessions: Methodological problems; Origins of parasitism - co-evolution of parasites, vectors and hosts; Biogeographical associations. It should be emphasised that such headings were deliberately broad and that considerable cross-session discussion occurred.

As might be expected, it is difficult to quantify the exact degree of progress achieved towards the original objectives of the meeting, suffice to say that the meeting produced much lively and informed debate resulting in the selection of papers included in this edition of the Memórias do Instituto
Oswaldo Cruz; abstracts for all papers are available at Exeter (www.ex.ac.uk/biology/meeting/ index.htm). The chairmen, John Baker, Michael Miles, Hooman Momen, and support staff at the Pathogen Molecular Biology \& Biochemistry Unit, London School of Hygine and Tropical Medicine and the University of Exeter are to be congratulated on an excellent meeting.

\section{ACKNOWLEDGEMENTS}

To my co-organisers, Wendy Gibson, Harry Noyes, Chris Schofield, Michael Miles and John Baker, for their help and support throughout.

\section{REFERENCES}

Baker JR 1963. Speculations on the evolution of the family Trypanosomatidae Doflein, 1901. Exp Parasitol 13: 219-233.

Hoare CA 1972. The Trypanosomes of Mammals, Blackwell, Oxford, 749 pp.

Léger L 1904. Les affinités de l'Herpetomonas subulata et la phylogènie des trypanosomes. $C R$ Soc Biol 57: 615-617.

Minchin EA 1908. Investigations on the development of trypanosomes in the tsetse flies and other Diptera. Q J Microsc Sci 52: 159-260.

Stevens JR, Noyes HA, Dover GA, Gibson WC 1999. The ancient and divergent origins of the human pathogenic trypanosomes, Trypanosoma brucei and T. cruzi. Parasitology 118: 107-116.

Stevens JR, Noyes HA, Schofield CJ, Gibson W 2000. The molecular evolution of Trypanosomatidae. $A d v$ Parasitol 48: 1-54. 